\title{
INDEKS NUTRISI DAN KESINTASAN LARVA SPODOPTERA LITURA F. YANG DIBERI PAKAN MENGANDUNG EKSTRAK KULIT JENGKOL (PITHECELLOBIUM LOBATUM BENTH.)
}

\author{
Trisnowati B. Ambarningrum ${ }^{1}$, Hery Pratiknyo ${ }^{1}$, dan Slamet Priyanto ${ }^{2}$
}

\begin{abstract}
Nutrition indices and survivorship of Spodoptera Litura $F$. larvae is fed nutrition including jengkol bark extract (Pithecellobium Lobatum Benth). The effect of P. lobatum barks extract on nutrition indices and survivorship S. litura larvae has been investigated. Nutrition indices were observed by giving fifth-instar larvae one of the three diets, every group of diet was added various concentration of barks extract, containing either $1.10 ; 2.20$; or $4.40 \%$. Survivorship were observed by giving first-instar larvae one of the three diets, every group of diet was added various concentration of barks extract, containing either $0.6 ; 1.2$; or $2.4 \%$. The result showed that, the Relative Consumption Rate (RCR), Relative Growth Rate (RGR), Efficiencies of food use (ECD and ECI) value of larvae treated were significantly lower in the case of treated larvae than that of the controls, Approximate Digestibility (AD) value of larvae treated were significantly higher in the case of treated larvae than that of the controls and decrease of survivorship tested larvae.
\end{abstract}

Key words : Nutrition indices, survivorship, Spodoptera litura larvae, barks extracts

\section{PENDAHULUAN}

Salah satu serangga hama yang berpotensi menyerang tanaman kedelai adalah Spodoptera litura F. Serangan serangga tersebut telah menyebabkan kehilangan hasil yang tidak sedikit. Menurut Kalshoven (1981) larva serangga tersebut juga menyerang tanaman kol, kapas, kacang-kacangan, tomat, dan tanaman sayuran lainnya. Selanjutnya Kalshoven (1981) menyatakan bahwa larva $S$. litura bersifat polifag dan mempunyai banyak tanaman inang. Disamping sifat polifagnya, perkembangan larva serangga tersebut juga cukup cepat dan fekunditasnya cukup tinggi. Serangga ini dapat menghasilkan lebih dari dua generasi dalam satu tahun, sehingga memungkinkan makanan yang dikonsumsinya menjadi tinggi serta jumlah tanaman yang dirusak juga cukup banyak.

Usaha pengendalian serangga hama ini telah lama diupayakan dan pernah mencapai hasil yang menggembirakan dengan digunakannya berbagai macam insektisida sintetis, namun ternyata penggunaan insektisida sintetis yang tidak tepat dan berlebihan telah mengakibatkan terbentuknya resistensi pada serangga hama terhadap berbagai jenis insektisida (Metcalf \& Luckmann, 1982).
Tumbuhan dipilih sebagai sumber insektisida, karena insektisida yang dihasilkan bersifat selektif dan mudah terurai (Rejesus \& Tantengco, 1986). Buah jengkol sudah lama dikenal masyarakat sebagai bahan pangan. Jengkol merupakan tumbuhan khas Asia Tenggara dan biasa ditemukan dengan mudah di seluruh wilayah Indonesia (Wikipedia, 2007). Kulit keras buah jengkol sampai saat ini masih merupakan limbah yang tidak termanfaatkan dan tidak mempunyai nilai ekonomi, padahal kulit jengkol mengandung beberapa senyawa allelokimia dan berpeluang untuk digunakan sebagai insektisida botani. Kulit jengkol mengandung senyawasenyawa aktif seperti alkaloid, terpenoid, dan asam fenolat (Rahayu \& Pukan, 1998). Penelitian menggunakan ekstrak kulit jengkol pernah dilakukan, namun penelitian tersebut hanya diarahkan untuk mengetahui konsentrasi efektif yang dapat menyebabkan mortalitas yang tinggi dari serangga uji, sedangkan bagaimana pengaruhnya terhadap indeks nutrisi dan kesintasan dari serangga uji belum dilakukan. Pengukuran indeks nutrisi penting untuk diketahui, karena menggambarkan pola pemanfaatan makanan dari serangga uji.

\footnotetext{
${ }^{1}$ Laboratorium Entomologi-Parasitoid, Fakultas Biologi, Universitas Jenderal Soedirman, Jl. Dr. Soeparno Grendeng Purwokerto 53123 Purwokerto. Email : trisnowatibudi@yahoo.com

${ }^{2}$ Laboratorium Ekotoksikologi, Fakultas Biologi, Universitas Jenderal Soedirman,

Jl. Dr. Soeparno Grendeng Purwokerto 53123 Purwokerto
} 
Untung (1996) menyatakan bahwa pengaruh senyawa-senyawa kimia yang terkandung dalam insektisida yang diberikan dapat dilihat melalui pertumbuhan, nilai nutrisi, dan fekunditas dari serangga uji. Diharapkan ekstrak kulit jengkol yang dicampurkan dalam pakan buatan larva S. litura memiliki efek toksik dan menurunkan nafsu makan larva serangga tersebut, sehingga akan mempengaruhi indeks nutrisi larva $S$. litura. Jika pemberian ekstrak kulit jengkol tersebut mampu mempengaruhi indeks nutrisi dan kesintasan larva S. litura, diharapkan populasi serangga tersebut dapat dikendalikan, sehingga akan meminimalkan kerugian yang ditimbulkan oleh aktivitas makan larva S. litura.

\section{METODE PENELITIAN}

Penelitian dilakukan di Laboratorium EntomologiParasitologi, Fakultas Biologi, Universitas Jenderal Soedirman Purwokerto pada bulan April sampai Oktober 2007.

Pengukuran Indeks Nutrisi. Metode pengukuran indeks nutrisi mengacu pada metode gravimetri Waldbauer (1968). Awal pengujian disiapkan pakan buatan untuk larva $S$. litura, masing-masing dengan empat macam konsentrasi perlakuan, yaitu $0 ; 1,10 ; 2,20$; dan $4,40 \%$. Penetapan konsentrasi perlakuan ini berdasarkan uji toksisitas terhadap konsentrasi yang menyebabkan kematian larva instar V sebesar 50\% $\left(\mathrm{LC}_{50}\right)$. Konsentrasi tertinggi yang digunakan adalah konsentrasi $\mathrm{LC}_{50}$, untuk selanjutnya dibagi dua sehingga diperoleh tiga konsentrasi dengan kisaran yang sama.

Larva uji yang digunakan adalah larva instar $\mathrm{V}$ yang baru ganti kulit dan belum makan. Pengukuran indeks nutrisi larva instar V S. litura diawali dengan menimbang larva tersebut untuk mengetahui berat basah awal, kemudian larva ditempatkan secara individual dalam vial, dengan satu potong pakan buatan yang mengandung ekstrak dengan konsentrasi tertentu dan yang telah diketahui berat basah awalnya. Pengamatan dilakukan setiap 24 jam sekali dan perlakuan diakhiri pada saat larva mencapai tahap instar $\mathrm{V}$ akhir, yang ditandai dengan berhentinya aktivitas makan. Selanjutnya larva, sisa pakan, dan feses dari masingmasing vial dibungkus kertas aluminium, untuk dikeringkan dalam oven bersuhu $60^{\circ} \mathrm{C}$ sampai mencapai berat kering yang konstan.

Berat kering awal pakan yang diberikan untuk setiap perlakuan dan berat kering awal larva dihitung dengan mengeringkan dua puluh buah aliquot pakan untuk setiap kelompok konsentrasi perlakuan yang digunakan dan dua puluh ekor larva instar $\mathrm{V}$ yang baru ganti kulit dan belum makan (aliquot larva). Pengeringan dilakukan di dalam oven bersuhu $60^{\circ} \mathrm{C}$, sampai dicapai berat kering yang konstan. Dengan demikian berat kering awal pakan yang digunakan untuk setiap perlakuan dapat dihitung dengan mengalikan rata-rata berat kering awal pakan (aliquot pakan) dengan berat basah awalnya. Berat kering awal larva dihitung dengan mengalikan rata-rata berat kering awal larva (aliquot larva) dengan berat basah awalnya.

Jumlah pakan yang dikonsumsi larva selama periode makan dapat dihitung dengan mengukur selisih antara berat kering awal pakan dengan berat kering sisa pakan. Pertambahan berat larva yang diperoleh selama perlakuan diperoleh dari pengurangan berat kering larva setelah perlakuan dengan berat kering awal larva.

Respon kompensasi larva instar V S. litura terhadap adanya ekstrak kulit jengkol dalam pakannya dapat dihitung dengan metode gravimetri dari Waldbauer (1968), dengan rumus sebagai berikut :

1. Laju pertumbuhan relatif (Relative Growth Rate/ RGR)

$\mathrm{RGR}=\mathrm{G} / \mathrm{TA}$ ( $\mathrm{g} / \mathrm{g}$ berat badan / hari $)$

2. Laju konsumsi relatif (Relative Consumption Rate/ $\mathrm{RCR}$ )

$\mathrm{RCR}=\mathrm{F} / \mathrm{TA}(\mathrm{g} / \mathrm{g}$ berat badan / hari $)$

3. Efisiensi konversi makanan yang dicerna (Efficiency of Conversion of Digested food/ECD) $\mathrm{ECD}=\mathrm{G} /(\mathrm{F}-\mathrm{f}) \times 100 \%$

4. Efisiensi konversi makanan yang dimakan (Efficiency of Conversion of Ingested food/ECI) $\mathrm{ECI}=\mathrm{G} / \mathrm{F} \times 100 \%$

5. Perkiraan makanan yang dicerna (Approximate Digestibility/AD)

$\mathrm{AD}=(\mathrm{F}-\mathrm{f}) / \mathrm{F} \times 100 \%$

Keterangan :

$\mathrm{G}$ = Pertambahan berat larva selama periode makan, diperoleh dari pengurangan berat kering akhir larva dengan berat kering awal larva

$\mathrm{F}$ = Jumlah pakan yang dikonsumsi, diperoleh dari pengurangan berat kering awal pakan dengan berat kering akhir pakan

$\mathrm{f}=$ Berat kering feses

$\mathrm{T}$ = Lamanya waktu makan

A = Berat rata-rata larva selama perlakuan, diperoleh dari penambahan berat kering awal larva dengan berat kering akhir larva kemudian dibagi dua 
Pengujian Kesintasan. Pada awal pengujian disiapkan pakan buatan larva $S$. litura masing-masing dengan empat macam konsentrasi perlakuan, yaitu konsentrasi $0 ; 0,6 ; 1,2 ;$ dan $2,4 \%$. Penetapan konsentrasi perlakuan ini berdasarkan uji toksisitas terhadap konsentrasi yang menyebabkan kematian larva instar I sebesar 50\% $\left(\mathrm{LC}_{50}\right)$. Konsentrasi tertinggi yang digunakan adalah konsentrasi $\mathrm{LC}_{50}$, untuk selanjutnya dibagi dua sehingga diperoleh tiga konsentrasi dengan kisaran yang sama.

Larva yang digunakan untuk pengujian kesintasan adalah larva instar I yang baru menetas dari telur dan ditempatkan secara individual. Pengamatan dilakukan setiap hari untuk mengamati perubahan instar, jumlah larva yang mati dan masih hidup pada setiap instar, lamanya masa larva, serta jumlah larva yang berhasil menjadi pupa.

Rancangan percobaan yang digunakan dalam penelitian ini adalah Rancangan Acak Lengkap (RAL). Pengukuran indeks nutrisi berupa pemberian pakan buatan yang mengandung ekstrak kulit jengkol dengan empat konsentrasi, yaitu $0 ; 1,10 ; 2,20$; dan 4,40\%. Masing-masing perlakuan diulang lima kali dan setiap ulangan terdiri dari empat ekor larva uji (instar V) yang ditempatkan secara individual, sedangkan untuk pengujian kesintasan dilakukan dengan pemberian pakan buatan yang mengandung ekstrak kulit jengkol dengan konsentrasi $0 ; 0,6 ; 1,2 ;$ dan 2,4\%. Masing-masing perlakuan diulang lima kali dan setiap ulangan terdiri dari 6 larva uji (instar I) yang ditempatkan secara individual. Data yang diperoleh dianalisis dengan sidik ragam, dilanjutkan dengan uji lanjut Duncan.

\section{HASIL DAN PEMBAHASAN}

Pengukuran Indeks Nutrisi. Hasil pengukuran indeks nutrisi larva instar V S. litura yang diberi pakan mengandung ekstrak kulit jengkol seperti yang tertera pada Tabel 1, dimana memperlihatkan bahwa secara umum semua konsentrasi ekstrak kulit jengkol yang diberikan mampu menurunkan RCR larva uji, kecuali pada konsentrasi 1,10\% nilai RCR larva uji sedikit lebih tinggi dibandingkan RCR larva kontrol, namun secara statistik tidak berbeda nyata dibandingkan kontrol. Hal tersebut mungkin disebabkan pakan yang mengandung ekstrak kulit jengkol pada konsentrasi $1,10 \%$ masih berada pada batas yang normal untuk dikonsumsi, sehingga belum mempengaruhi nilai RCR larva uji. Nilai RCR larva uji pada pemberian ekstrak kulit jengkol mulai konsentrasi 1,10-4,40\% berturut-turut adalah 1,69; 1, 60; dan $1,36 \mathrm{~g} / \mathrm{g}$ berat badan/hari.

Persentase penurunan RCR larva uji pada konsentrasi 2,20 dan 4,40\% adalah sebesar 3,61 dan $18,07 \%$. Menurunnya jumlah pakan yang dikonsumsi larva disebabkan adanya kandungan senyawa allelokimia dalam ekstrak kulit jengkol yang diberikan melalui pakannya. Slansky \& Scriber (1985) mengatakan bahwa larva serangga akan menurunkan jumlah pakan yang dikonsumsi bila terdapat senyawa yang bersifat toksik dalam pakannya. Dikatakan pula bahwa bila terdapat senyawa toksik dalam pakannya, pada mulanya mungkin tidak mempengaruhi jumlah pakan yang dikonsumsi, namun setelah tubuh merasa terganggu maka serangga mulai melakukan respon dengan cara mengurangi jumlah

Tabel 1. Laju konsumsi relatif (RCR) dan laju pertumbuhan relatif (RGR) larva instar V S. litura akibat pemberian pakan yang mengandung ekstrak etanol kulit jengkol

\begin{tabular}{ccc}
\hline $\begin{array}{c}\text { Kons } \\
(\%)\end{array}$ & $\begin{array}{c}\text { RCR } \\
(\mathrm{g} / \mathrm{g} \text { berat badan/hari })\end{array}$ & $\begin{array}{c}\text { RGR } \\
(\mathrm{g} / \mathrm{g} \text { berat badan/hari })\end{array}$ \\
\hline 0 & $1,66 \pm 0,27 \mathrm{a}$ & $0,25 \pm 0,06 \mathrm{a}$ \\
1,10 & $1,69 \pm 0,44 \mathrm{a}$ & $0,15 \pm 0,04 \mathrm{~b}$ \\
2,20 & $1,60 \pm 0,46 \mathrm{ab}$ & $0,14 \pm 0,04 \mathrm{bc}$ \\
4,40 & $1,36 \pm 0,39 \mathrm{~b}$ & $0,11 \pm 0,34 \mathrm{c}$ \\
\hline
\end{tabular}

Keterangan : Semua nilai rata-rata \pm SD. Nilai rata-rata dalam satu kolom yang diikuti oleh huruf kecil yang sama, tidak berbeda nyata (ANOVA, dilanjutkan uji Duncan, pada $\mathrm{p}<0,05$ ) 
Tabel 2. Efisiensi konversi makanan yang dicerna (ECD), efisiensi konversi makanan yang dimakan (ECI), serta perkiraan jumlah makanan yang dicerna (AD) larva instar V S. litura akibat pemberian pakan yang mengandung ekstrak etanol kulit jengkol

\begin{tabular}{cccc}
\hline $\begin{array}{c}\text { Kons } \\
(\%)\end{array}$ & $\begin{array}{c}\text { ECD } \\
(\%)\end{array}$ & $\begin{array}{c}\text { ECI } \\
(\%)\end{array}$ & $\begin{array}{c}\text { AD } \\
(\%)\end{array}$ \\
\hline 0 & $31,95 \pm 4,25 \mathrm{a}$ & $22,60 \pm 2,27 \mathrm{a}$ & $47,43 \pm 5,44 \mathrm{a}$ \\
1,10 & $23,20 \pm 3,39 \mathrm{~b}$ & $17,61 \pm 3,01 \mathrm{~b}$ & $50,82 \pm 6,92 \mathrm{ab}$ \\
2,20 & $22,90 \pm 5,07 \mathrm{~b}$ & $17,62 \pm 2,91 \mathrm{~b}$ & $52,98 \pm 8,66 \mathrm{~b}$ \\
4,40 & $22,52 \mathrm{~b} \pm 0,55 \mathrm{~b}$ & $17,28 \pm 3,21 \mathrm{~b}$ & $52,96 \pm 8,55 \mathrm{~b}$ \\
\hline
\end{tabular}

Keterangan : Semua nilai rata-rata \pm SD. Nilai rata-rata dalam satu kolom yang diikuti oleh huruf kecil yang sama, tidak berbeda nyata (ANOVA, dilanjutkan uji Duncan, pada $\mathrm{p}<0,05$ )

Tabel 3. Rata-rata masa larva, persentase larva yang terhambat perkembangannya, persentase pupa cacat, dan persentase kesintasan larva S. litura

\begin{tabular}{cccccc}
\hline $\begin{array}{c}\text { Konsentrasi } \\
(\%)\end{array}$ & $\begin{array}{c}\text { Masa Larva } \\
\text { (hari) }\end{array}$ & $\begin{array}{c}\text { Larva mati } \\
(\%)\end{array}$ & $\begin{array}{c}\text { Larva terhambat } \\
(\%)\end{array}$ & $\begin{array}{c}\text { Pupa cacat } \\
(\%)\end{array}$ & $\begin{array}{c}\text { Kesintasan } \\
(\%)\end{array}$ \\
\hline 0 & $34,07 \pm 0,83 \mathrm{a}$ & 0 & 3 & 0 & 97 \\
0,6 & $37,95 \pm 2,35 \mathrm{~b}$ & 33 & 17 & 7 & 43 \\
1,2 & $41,27 \pm 6,15 \mathrm{c}$ & 50 & 30 & 3 & 17 \\
2,4 & $51,79 \pm 4,76 \mathrm{~d}$ & 53 & 47 & 0 & 0 \\
\hline
\end{tabular}

Keterangan : Semua nilai rata-rata \pm SD. Nilai rata-rata dalam satu kolom yang diikuti oleh huruf kecil yang sama, tidak berbeda nyata (ANOVA, dilanjutkan uji Duncan pada $\mathrm{p}<0,05$ )

pakan yang dikonsumsinya. Hal ini merupakan usaha serangga untuk mengurangi jumlah racun yang masuk ke dalam tubuhnya

Ekstrak kulit jengkol secara umum juga mampu menurunkan RGR larva uji (Tabel 1). Mulai konsentrasi $1,1 \%$ sudah berbeda nyata dibandingkan kontrol. Nilai RGR larva uji pada pemberian ekstrak kulit jengkol mulai konsentrasi $1,10-4,40 \%$ berturut-turut adalah 0,$15 ; 0,14$; dan $0,11 \mathrm{~g} / \mathrm{g}$ berat badan /hari. Persentase penurunan RGR larva uji mulai konsentrasi $1,10-4,40 \%$ berturutturut adalah sebesar 40, 44, dan 56\%.

Penurunan RCR berpengaruh terhadap penurunan RGR. Menurunnya RCR menyebabkan pemasukan makanan yang diubah menjadi biomassa menjadi lebih sedikit. Bertambah atau berkurangnya berat larva dipengaruhi oleh besar kecilnya konsumsi total larva serangga. Banyak atau sedikitnya pakan yang dikonsumsi larva dipengaruhi oleh kualitas nutrisi dari pakan itu (Slansky \& Scriber, 1985). Adanya senyawa allelokimia yang bersifat toksik yang dikonsumsi serangga akan mempengaruhi jumlah dan laju konsumsinya, sehingga akan mempengaruhi pula laju pertumbuhan, berat akhir, dan kesintasan larva. Apabila pakan yang dikonsumsi mengandung senyawa toksik, maka larva tidak akan mencapai berat yang kritis untuk menjadi pupa (Simpson \& Simpson, 1990). Scriber \& Slansky (1981) mengatakan bahwa energi yang dihasilkan dari pakan yang telah dikonsumsi tidak semuanya dijadikan untuk menambah berat tubuh larva, tetapi sebagian akan digunakan oleh serangga untuk usaha detoksifikasi akibat adanya senyawa toksik dalam pakannya, sehingga berat tubuhnya menjadi turun.

Pemberian ekstrak kulit jengkol juga berpengaruh terhadap nilai ECD, ECI, dan AD larva uji. Nilai ECD dan ECI larva uji cenderung menurun dengan semakin meningkatnya konsentrasi ekstrak yang diberikan seperti terlihat pada Tabel 2. Persentase penurunan nilai ECD larva uji dari konsentrasi 1,10-4,40\% berturut-turut sebesar 27,39; 28,32; dan 29,51\%, sedangkan persentase penurunan nilai ECI dari konsentrasi $1,10-4,40 \%$ berturut-turut sebesar 22,08; 22,03; dan 23,54\%. 
Simpson \& Simpson (1990) mengungkapkan bahwa jika serangga tidak mungkin menyeleksi makanannya, karena tidak tersedianya variasi makanan, maka konsekuensi yang muncul adalah kompensasi pada efisiensi makanan yang dicerna dan yang dimakan (ECD dan ECI). Menurunnya ECD disebabkan serangga mengeluarkan metabolic cost untuk detoksifikasi senyawa allelokimia yang bersifat racun di dalam pakan yang dikonsumsinya, sehingga laju pertumbuhannya juga terganggu (Scriber \& Slansky, 1981).

Untuk mengimbangi rendahnya makanan yang dikonsumsi dan turunnya nilai ECD, salah satu jalan adalah dengan meningkatkan jumlah makanan yang dicerna $(\mathrm{AD})$ agar pertumbuhan larva tidak terganggu seperti yang terlihat pada Tabel 2. Nilai AD larva uji dari konsentrasi 1,10-4,40\% adalah 50,82; 52,98; dan $52,96 \%$, dengan persentase peningkatan nilai $\mathrm{AD}$ berturut-turut sebesar 7,15; 11,70; dan 11,66\%.

Menurunnya ECI dan ECD menyebabkan pakan dalam usus terpapar lebih lama dengan enzim pencernaan, sehingga nilai ADnya meningkat. Di lain pihak kebutuhan akan energi tetap mendesak untuk berbagai aktivitas seperti pertumbuhan, perkembangan, pergerakan, dan untuk usaha detoksifikasi, sehingga serangga akan memperolehnya dengan cara meningkatkan nilai AD (Slansky \& Scriber, 1985). Peningkatan nilai AD dapat terlihat dengan melihat jumlah feses yang dikeluarkan dari larva uji. Diduga feses yang dikeluarkan oleh larva selain berasal dari sisa-sisa hasil pencernaan yang tidak terserap, juga berasal dari membran peritrofik yang hancur akibat adanya senyawa allelokimia dalam makanannya. Pyensor (1980) menyatakan bahwa alkaloid dapat menyebabkan iritasi pada saluran pencernaan dengan merusak membran peritrofik saluran pencernaan larva uji. Gershenzon \& Croteau (1991) mengatakan bahwa senyawa saponin dapat menurunkan aktivitas enzim protease dalam saluran pencernaan makan serangga, sehingga mempengaruhi proses penyerapan makanan, akibatnya makanan yang masuk tidak dapat diserap dan langsung dikeluarkan dalam bentuk feses.

Dari uraian tersebut di atas terlihat bahwa larva instar V S. litura melakukan respon kompensasi dengan adanya senyawa allelokimia dalam pakan yang dikonsumsinya. Respon tersebut berupa penurunan laju konsumsi (RCR) yang diimbangi dengan meningkatnya perkiraan jumlah makanan yang dicerna (AD). Terlihat pula penurunan nilai ECD yang menyebabkan nilai RGR menurun pula. Demikian pula nilai ECI menurun, sesuai dengan pola penurunan ECD.

Pengujian Kesintasan. Tabel 3 memperlihatkan lama larva, persentase larva mati, persentase larva terhambat, persentase pupa cacat, dan persentase kesintasan larva uji. Terlihat bahwa persentase kesintasan larva uji semakin menurun dengan semakin meningkatnya konsentrasi. Pada konsentrasi 2,4\% tidak ada larva yang berhasil menjadi pupa, hal ini disebabkan larva uji mengalami gangguan pada saat ekdisis, sehingga semua larva tidak tumbuh dan berkembang menjadi instar berikutnya. Pada konsentrasi 0,6 dan $1,2 \%$ banyak larva yang mati dan terbentuk pupa cacat, sedangkan pada konsentrasi $2,4 \%$ banyak larva yang mati dalam bentuk peralihan larva-pupa, dengan ciri-ciri antara lain terjadi sklerotisasi pada sebagian tubuhnya dan terjadinya perubahan warna menjadi lebih gelap. Terlihat pula pada Tabel 3 dengan semakin meningkatnya konsentrasi, maka masa larva semakin lama.

Hasil tersebut menunjukkan bahwa ekstrak kulit jengkol dapat mengganggu proses pergantian kulit larva uji. Terganggunya proses pergantian kulit akibat pemberian ekstrak kulit jengkol diduga karena kandungan saponin dalam ekstrak tersebut. Terdapatnya saponin dalam ekstrak kulit jengkol akan mengikat sterol dalam saluran pencernaan makanan. Menurut Gershenzon \& Croteau (1991) pengikatan sterol dalam pencernaan makanan akan menurunkan laju sterol dalam hemolimfa. Satu peran penting sterol bagi serangga adalah sebagai prekursor dari hormon ekdison, sehingga dengan menurunnya persediaan sterol maka proses pergantian kulit pada serangga juga akan terganggu.

Lamanya masa perkembangan larva menjadi pupa merupakan salah satu kompensasi karena nilai RCR serangga uji yang menurun (Slansky, 1993). Hal ini terjadi karena larva mengkonsumsi pakan yang kurang optimal, yang disebabkan pakan mengandung senyawa allelokimia. Akibatnya terjadi gangguan pada pertumbuhan dan perkembangannya. Pada kondisi tersebut serangga berusaha mengurangi gangguan yang terjadi dengan cara memperpanjang masa perkembangannya dan berusaha menjadi pupa, namun tidak berhasil dan akhirnya mati (Slansky, 1993). 


\section{SIMPULAN}

Ekstrak kulit jengkol mampu menurunkan laju konsumsi relatif (RCR), laju pertumbuhan relatif (RGR), Efisiensi pemanfaatan makanan (ECD dan ECI), meningkatkan perkiraan jumlah makanan yang dicerna (AD) larva instar V S. litura, serta menurunkan kesintasan larva uji.

\section{SANWACANA}

Terimakasih kepada Direktorat Pembinaan Penelitian dan Pengabdian kepada masyarakat Direktorat Jenderal Pendidikan Tinggi Departemen Pendidikan Nasional atas dana Hibah Bersaing XV tahun 2007-2008 yang diberikan.

\section{DAFTAR PUSTAKA}

Gershenzon, J. \& R. Croteau. 1991. Terpenoid. Pages 165-209. in G.A. Rosenthal \& M.R. Barenbaum, eds. Herbivores, their interaction with secondary plant metabolites. $2^{\text {nd }}$ edition. Academic Press, New York.

Kalshoven, L.G.E. 1981. The Pests of Crops in Indonesia. PT Ichtiar Baru- Van Hoeve, Jakarta.

Metcalf, R.L. \& W.H. Luckmann. 1982. Introduction to Insect Pest Management. John Willey \& Sons, New York.

Pyenson, L. 1980. Fundamental of entomology and plant pathologi. $2^{\text {nd }}$ edition. AVI publishing. AVI Publishing Company, Westport-Connecticut.

Rahayu, E.S. \& K. K. Pukan. 1998. Kandungan senyawa alelokemi kulit buah Pithecellobium lobatum Benth. (jengkol) dan pengaruhnya terhadap pertumbuhan beberapa gulma padi. Laporan Penelitian (tidak dipublikasikan). FPMIPA IKIP Semarang, Semarang.
Rejesus, B.M. \& G.B. Tantengco. 1986. Survey of Philippines plants for insecticidal activity.2. Biological of fower and leaf extract from six species of plants on insect. Coll. Laguna (Philipphines).

Simpson, S.J. \& C.L. Simpson. 1990. The mechanism of nutritional compensation by phytophagus insect. Pages 111-160. In: Insect-Plant Interaction. Vol.2. CRC Press, Florida.

Slansky, F. Jr. 1993. Nutritional ecology: the fundamental quest for nutrient. Pages 29-73. In: N.E. Stamp \& T.M. Casey, eds. Catterpilars, Ecology, \& Evolutionary Constrain on Foraging. Chapman \& Hall, New York.

Slansky, F. Jr. \& J.M. Scriber. 1985. Food consumption and utilization. Pages 88-122. In: G.A. Kerkut \& L.I. Gilbert, eds. ComprehensiveIinsect Physiology,Biochemestry, and Pharmacology. Vol.4. Pergamon Press.

Scriber, J.M. \& Slansky, F. Jr. 1981. The nutritional ecology of immature insects. Ann. Rev. Entomol. $26: 183-211$.

Untung, K. 1996. Pengantar Pengelolaan Hama Terpadu. Gadjah Mada University Press. Yogyakarta.

Wikipedia Indonesia. 2007. Jering. Jering. http://id. Wikipedia.org/wiki/jering. Diakses tanggal 1 Juni 2007.

Waldbauer, G.P. 1968. The consumption and tulization of food by insect. Pages. 229-288. In: J.W.L. Beament; J.E. Treherne \& V.B. Wiglessworth, eds. Advances insect physiology. Academic Press, London. 